\title{
Philosophical and Biological Foundation of Brain Based Learning: A Phenomenological Approach
}

\author{
Fozia Fatima ${ }^{1}$, Sabir $\mathrm{Ali}^{2}$
}

\begin{abstract}
This investigation was undertaken to look at the philosophical and biological foundation of brain based learning through phenomenological approach. Subjective method of investigation was used. Interviews were taken through semi-structures procedure in which 12 instructors were involved as a sample. Two topics of the examination were assessed and it was discovered that authenticity, optimism, realism, dualism, naturalism, cognizant and oblivious part of cerebrum and constructivism were straightforwardly related with brain oriented learning approach. Correspondingly, Brain is not organically comprehended by the educator completely in light of the fact because cerebrum discovery is tranquil as a young ground of teaching learning process. Instructor have been rehearsing cerebrum based adapting normally yet they are not ready to express a reasonable balanced for their activity yet the educators still practice the mind based adapting adequately.
\end{abstract}

Keywords: Brain-Based Learning, Philosophical and Biological Foundation, Phenomenological Study.

\section{Introduction}

An individual mind works according to the specific patterns of thoughts. Our thought of work would be changed through the violation of belief conviction. It means that brain works under natural setting and it is directly associated with the neuroscience. It is a field of science that is legitimately connected with mind. It is also utilized to explain the principle thought of brain based learning into instructive setting. A concept of brain based learning is developed by a connection between individual's mind information and educational development of learner under natural setting of learning (Fatima, 2019).

\footnotetext{
${ }^{1}$ Assistant Professor, Department of Health Professions Education, National University of Medical Sciences, PWD Campus, Islamabad, Email: fozia.fatima@numspak.edu.pk ${ }^{2}$ Deputy Registrar Academic, University of Baltistan, Sakrdu, Gilgit-Baltistan, Pakistan Email: dr_sabir@outlook.com
} 
This new replica of knowledge regarding brain based philosophy has an incredible implication on educationalists and apprentices in their teaching learning process (Jensen, 2006). Various regions of brain directly affected with different mind-set, consciousness or recollection of the individuals (Hassan, 2013). It has been found that a theory of brain based learning is not a time consuming process because time is flexible in it and there is a consistency between teaching strategies and ongoing questioning and analysis from teachers to their students in it (Klinek, 2009). Effectual education ensues when teachers have persistent time to modify, to observe and to apply a comprehensible and systematic practice of teaching over their pupils (Jensen, 2005). When a brain of individual is capable to create specific pattern and to organize all information then a learning process take places for him/ her (Slope, 2001). An activity of learning that has a tapered boundary of time and put a pressure of completion on the learners for their project can reduce the efficiency and effectiveness of that task (Fatima \& Ali, 2019). The order of instructions from a teacher can stop or disturb natural patterning skill of students' brain (Hattie, 1992). Teaching impulse must be thematic that must be documented in which apprentices can establish an inventive and consistent understanding that is similar to their configurations of brain (Hassan, 2013).

It was seen that man was keen on loosening up the mysteries of cerebrum since old ages (Fatima, 2017). Mind was not comprehended as the focal organ of human working (Fatima, Zamir, Ali \& Fatima, 2018). It is directly linked with psychological procedure that has been pointed out by early rationalist, for example, Socrates, Plato and Aristotle (Gurian \& Stevens, 2004). Most recent research demonstrates that psyche and body act as joined and complex substance while though the early Greeks comprehended the brain, soul and mind to be completely isolated and individualistic approach (Cercone, 2006). Essentially, organic researchers additionally worked over the structure and capacity of brain and recognize that how various pieces of mind are associated with learning process (Rehman, 2011). In this examination, through phenomenological approach, researchers tried to discover the educator's observation about its philosophical and biological establishment of mind in the context of education.

\subsection{Statement of the Problem}

A very unusual advancement of knowledge has been initiated that facilitate in the designing of assessment, teaching and curriculum for the instructors today. This novel idea of brain based learning is not a formula for all learning. It is recycled to develop schemes that are ashore with the current advancement in learning process. It is the support for many transformational efforts in learning today but mostly educators do not apprehend its accurate 
significance in the context of Pakistani educational system. The live involvement of instructors who had straightforwardly executed brain based learning was explored by this phenomenological examination. This viewpoint ought to encourage the comprehension of why brain based learning practice and how instructor attempt to manage it by investigating their philosophical and natural comprehension about brain based learning.

\subsection{Objectives of the Study}

Following are the objectives of this study;

1. To examine philosophical perspective of teachers about brain based learning.

2. To determine teachers' knowledge about the biological foundation of brain based learning principles that they were practicing within their classrooms.

\section{Literature Review}

It was discovered that two basic ways of thinking, for example, authenticity and optimism were used to clarify the genuine idea of reality which turned out through the battle of Aristotle and Plato in Greek (Fatima, 2017). It may come through either discernible sign or from those thoughts which were present in our brains (Pintrich \& Schunk, 1996). It implies that truthful highlights and genuine pictures of anything are perceived with the assistance of mind which is straightforwardly identified or connected with our environment (Klinek, 2009). Both these ways of thinking of psyche were valuable in the life of an individual (Fatima, 2019; Hassan, 2013).

Descartes proposed an origination of dualism where the body is comprehended as an unmistakable thing of mind in the seventeenth Century (Hattie 1992). It was similarly observed that mental demonstrations were just like a machine with certain capacity that must be clarified by the logical principles of conduct, expelled feeling and considered as futile thing in the life of an individual (Damasio, 1999). In twentieth century, after a detail hypothetical examination about the psyche and body collaboration, it was seen that the issues of brain and body association was additionally partitioned into two submeasurements of reasoning of mind which were following;

1. Materialistic approach of body and brain of an individual.

2. Individual's dualistic approach of body and mind (Bhalla, 1999; Fatima 2019).

However, the precise picture of brain's role in individual life is not given by the above mentioned aspects of brain's philosophy because many contradictions about the interaction of mind and body of a person have been existed (Fatima \& Ali, 2015). Following are the current and everlasting controversies about the philosophy of mind;

1. The Mind-Body problems that was known as "Russellian Monism" 
2. Association between consciousness and phenomenology of moods.

3. Nature of Consciousness (Kriegel, 2014).

It was found a hope that helps to create a view about the materialism which can overcome a descriptive hole in the middle of a consciousness and substance (Fatima \& Ali, 2016). It was observed that dualism may help to overcome the casual passivity of mind vis-à-vis matter (Fatima, 2016). Therefore, sociologically speaking, it is highlighted the concept of "Russellian monism" (Leibniz, 2003). It can be said that the concept of "Russellian monism" based on both proto-mental and proto-physical countryside of object (Fatima et al., 2018). It can be realized as that earlier feature resolves the expressive fleabag among the two scopes of philosophy of concentration whereas side feature resolves the tricky situation of causal disinterest around the mind of the separate (Ali et al., 2018).

It was tentative that the philosophy of brain is not simply comprehensible till in the late $20^{\text {th }}$ era since the present and recurrent disagreements regarding the complications of body and mind connections produced many issues which bond together the problems of intentionality and awareness of an individual (Bhalla, 1999). It was observed that the actual relationship between the physical parts of brain and its environment were directly associated during the following approach to intentionality (Fatima, 2017). It contains three stages of understanding in which first one deals with purely materialistic, naturalistic and intentionality (Hattie, 1992). The "internationalist" or "representation list" theory of realization used in the succeeding phase of understanding and third stage deals with a reductive clarification of sensible knowledge (Damasio, 1999). In cooperation of intentionality and awareness can be directly linked with the materialism (Hart, 1983). Thus both are combined with materialism in the case of mind-body problem (Pintrich \& Schunk, 1996).

The brain acts as an enormously multifaceted organ and it has a strong and adaptive structure that return a massive amount of neural lattices or collection of neurons functioning together from which our daily life understanding is produced (Ali \& Fatima, 2016; Hassan, 2013).The mind's movement is especially impacted by legacies, expansion, commonality, frame of mind, condition and assessments of the individual (Ali \& Fatima, 2016). It is consistently under the influence of progress (Gardner, 1999). Therefore, in the 1980 's, pivotal specialized decisions have emerged around how intelligence comes to pass (Jensen, 2005). Various instruments are adequate by the technologists in gaining additional data about the structure and capacity of brain and their decisions empowering the spaces of enlightenment, learning and 
treatment on the grounds that upgrades information and commonality about the mind focused intellect (Cercone, 2006).

An anthropological mind involves modified parts as it is appeared in Figure 1. The common apportion of the mind is purified through water as the cerebrum. The cerebrum is the most exceedingly advanced piece of the mind, and once in a while absolved as the neo-cortex. Progressed and basic perceiving and profession development happens here. The common apportion of cerebrum consists of two halves of the globe that are related by a neural avenue, the corpus callosum (Cercone, 2006).

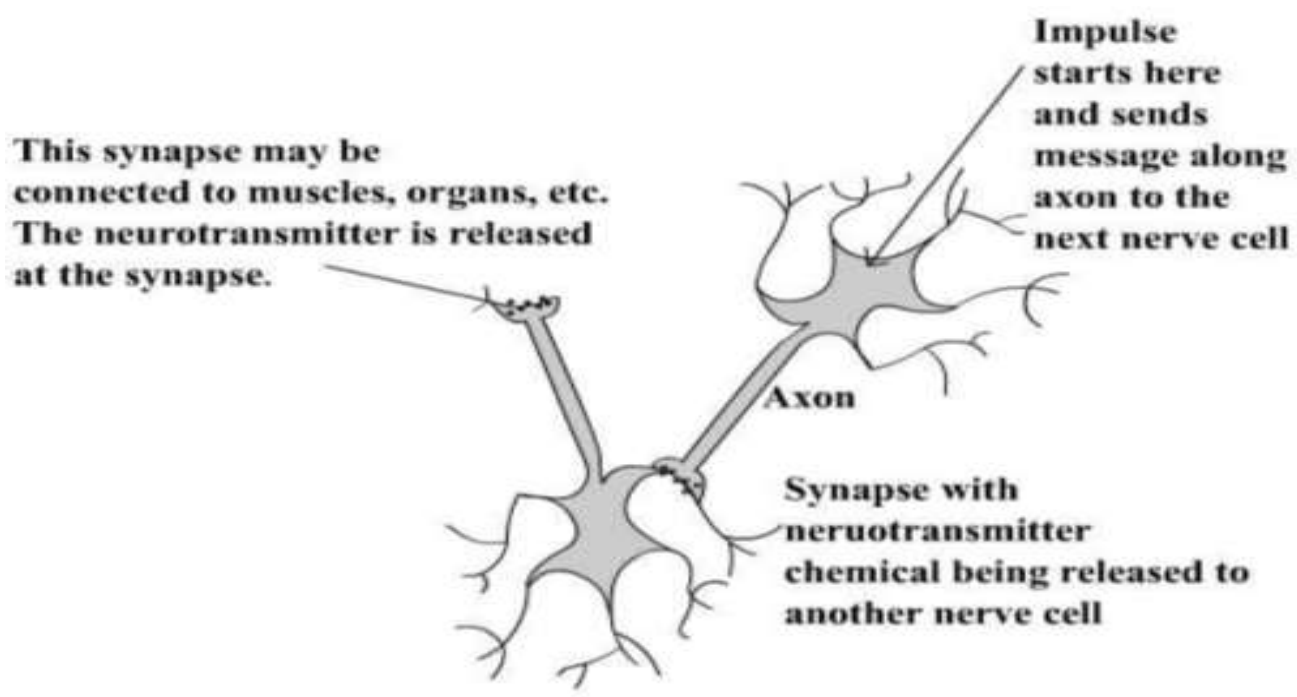

Neurons or nerve cells that connect at a synapse

Figure.1 Synaptic Process

Each side of cerebrum consists of four segments which are following as;

1) Visible or forward portion (motorized location, impulsivity, small period recalls, feeling, focused deed, mutual operational, creativity, forthcoming phonology).

2) Parietal portion (sensory location, judgment, trace (discomfort \& sickness, ability to temptation, reading and writing, craftiness).

3) Chronological portion (perceptible variety, small and extensive period recalls).

4) Occipital portion (judgments, vision) (Cercone, 2006). 


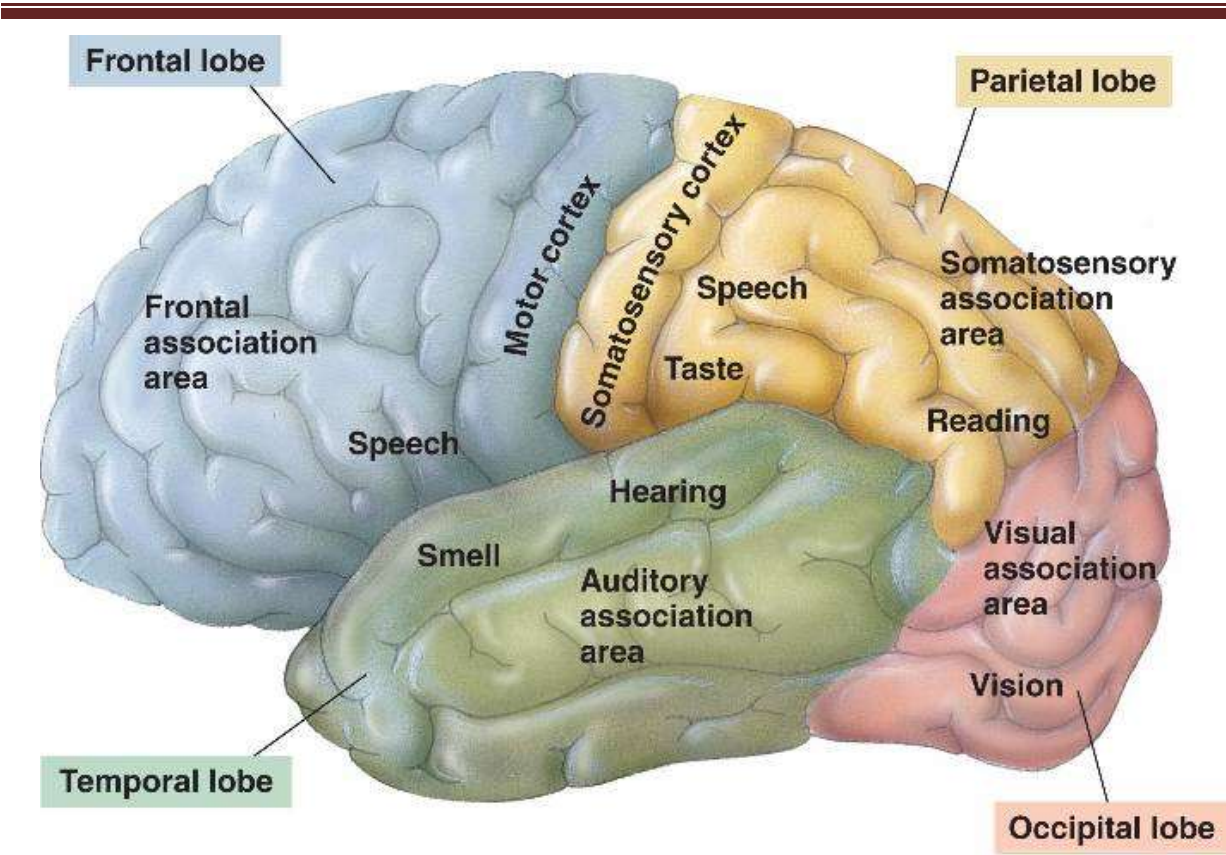

Figure 2. Sections of Humanoid Mind

Each hemisphere is responsible for clear activities (Cercone, 2006). The mid-brain section remains deep obscure the cerebrum and holds limbic organization, hypothalamus, hippocampus and amygdala. This area of mind is blessed as caretaker (Jensen, 2000). The pleasant portion of mind is blessed as hindbrain or mind stem. It is frequently considered as the primogenital and extreme budding portion of mind (Fatima, Ali \& Fatima, 2018). It is rarely named as the impassive mind that is responsible for our natural or fortitude deportments. This area of mind has a dominant character to reply to pain and it is cautious as the area of "flying or contest" response (Hassan, 2013). It was originated over many natural learning for example;

1) The mind is a computer (Fatima \& Zamir, 2015).

2) Education involves a process of complete working (Fatima \& Ali, 2015).

3) The exploration of sense is essential (Fatima \& Ali, 2016).

4) The exploration of sense happens through modeling (Ali \& Fatima, 2016).

5) Feelings are serious toward modeling (Fatima, 2016)

6) Each mind concurrently observes and forms by portions and aggregates (Fatima, 2017). 
7) Education includes both attentive consideration and outer perception (Ali et al., 2018).

8) Education includes sentient and insentient procedures (Fatima, 2019).

9) We have (at least) two kinds of remembrance methods: spatial and repetition of knowledge (Fatima \& Ali, 2019).

10) The mind recognizes and recalls best when realities and abilities are fixed in usual spatial remembrance (Caine \& Caine, 2005).

11) Education is improved by challenge and inhibited by threat (Hassan, 2013).

12) Each mind is exceptional (Fatima et al., 2018).

In sum, it can be assumed that with natural analysis of entity's mind, it was established that humanoid mind precisely work on brain based knowledge. A theory of brain based learning was developed by Caine in 2005. This theory had 12 principles that came out by an experimental study. According to this theory, there were three main dimensions such as experiences processing, experience enriched and relax alertness (Fatima, 2017). Each dimension contained four principle of brain based learning (Fatima \& Ali, 2019). A thorough and brief overview by above mentioned literature review, it was confirmed that brain based learning has strong philosophical and biological foundation. Teachers are practicing these principles in their respective classes intrinsically but they have no strong relational about their practices (Fatima, 2019). This study was intended to investigate that as teachers are practicing these principles then either they were aware about its philosophical and biological foundation or not in the context of Pakistan.

\subsection{Research Design}

\section{Research Methodology}

To control the metaphysical and natural foundation of brain based knowledge, phenomenological method was used. It was typically motivated to choice a marvel, connecting individual visions, involvements and prejudices (Fatima, 2016). It includes the spirit of existed practices of university educators about brain based knowledge. Through this qualitative approach, researchers recorded the live experiences of the teachers regarding brain based learning. By these recorded lived experiences help in determining the philosophical and biological foundation of brain based learning.

\subsection{Population and Sample}

This study was held at university level and from Islamabad universities researchers took 12 teachers through purposive sampling method, who were taught according to brain based learning philosophy at university level. The teachers were selected on the basis of their real experiences of the phenomena. 
They had organized meetings with 12 educators to confirm an acceptable sample size. Cresswell (2007) suggested only interrogating 10 defendants in order to gather wide facts about any phenomena are enough for analysis. After the meetings, only ten university educators were nominated as the sample. Meeting with selected teachers were held over two months throughout working hours in Islamabad universities. The sample involved five male and five female educators.

\subsection{Instrumentation}

Semi-structured interviews were made out of five key inquiries and it likewise enabled the analysts or the candidate to meander so as to pursue a thought in progressively extensive manner. The facet validity of interview was checked by five social science experts of National university of Modern languages, Islamabad.

\subsection{Data Collection}

Interviews were tape-recorded for later record. The meetings were diverse in durations, with shortest interview lasted for 15 minutes and the longest interview's time duration was 30 minutes. The whole process of data collection was sequential.

\section{Data Analysis and Interpretation}

Once the data collection was finished, researchers used a connecting technique that was complicated with their footage, personal intuition and views. This method allowed them to stay self-reflective during the study when seeing their role in the study relation to the defendants. Their diary also consists of the exploration terms and catalog that were referred to gain information from the literature review. Defendants' body language was also noted. This method of examination termed as thematic inspection.

Thematic analysis contained both inductive and deductive approach. Cluster additional information around the themes were analyzed by deductive approach while themes were derived through inductive reasoning. Horizontalization used to reread the records. All the removed parts were credited as equal values. The statements or horizons were then gathered into wider groups as sense units or theme. At last, the closing stage of the fact exploration involved the instinctive addition of the important written and physical explanation into united reports that told the mutual essentials of teachers' understandings about brain based learning. Thematic investigation produced 14 noteworthy articulations which researchers further analyzed to decide the basic subject. They had sorted six themes in this work.

\subsection{Body and Mind collaboration}

In the reaction to, first question some instructors said that we can do nothing or our performance is nothing if something materialistic is not available 
or have no physical appearance. They clarified that no one can comprehend the value of anything until they can perceive its physical appearance in the situated environment. This way of thinking is refers to realism. While the other way, dominant educators said that ".....specific kinds of scholarly musings revere a positive distinguish the appeared materialistic properties. The physical appearance of material is not essential that turn out through unique brain in light of fact that there were numerous things and thought comes in our mind have not something solid. While we can feel their goodness and Excellency."

\subsection{Mind and Attitude}

In response to second question, teachers accepted that experimental element of mind is the most significant part of their awareness. They said that the obviousness of understudies was regularly over shadowed by their enthusiastic life which is straightforwardly identified with their brain working. As they said that ".....the value of cognizance can be understood through different viewpoints like this idea of awareness and obviousness is related with their good and moral thought of life. It makes our lives intriguing and significant from social perspective. Our phenomenology of dispositions depended on single element of body and mind that was connected with the manner in which they strike us abstractly."

\subsection{Mind and Senses}

University teachers said that ".... insight regarding environment and their own recognition about him/her turned out using five faculties of reasoning procedure. They additionally accepted that learning happens through every day educational encounters and during encounters, person's brain goes about as channel since it forms any data as information that gets through the five detects which are then sorted out and builds up some develop." Through these builds, an individual comprehends a particular assortment of information about his/her environment. All these kinds of builds are altered with the progression of time in the life of human.

\subsection{Intellectual and Adaptation process}

University teachers believed that ".....a strong emotion, such as terror will induct the fight or flight physiologically and intellectual response. The response is impulsive because it is in place to protect life but not controlled by observing thought." They affirmed that expedition is compulsory for learning but too much knowledge will head to overwhelm. Though a stimulant is too potent then brain will enclose and drive into evolution state. Some students go into "adaptation state". It is due to testing. Students will not be capable to achieve in this stage if they have well read the objective covered in the test. In this way, multiplex procedure of judgment it is fated as papers, demonstrations, e- 
portfolios, case studies, and complication- depraved attainment apparatus which is used by them.

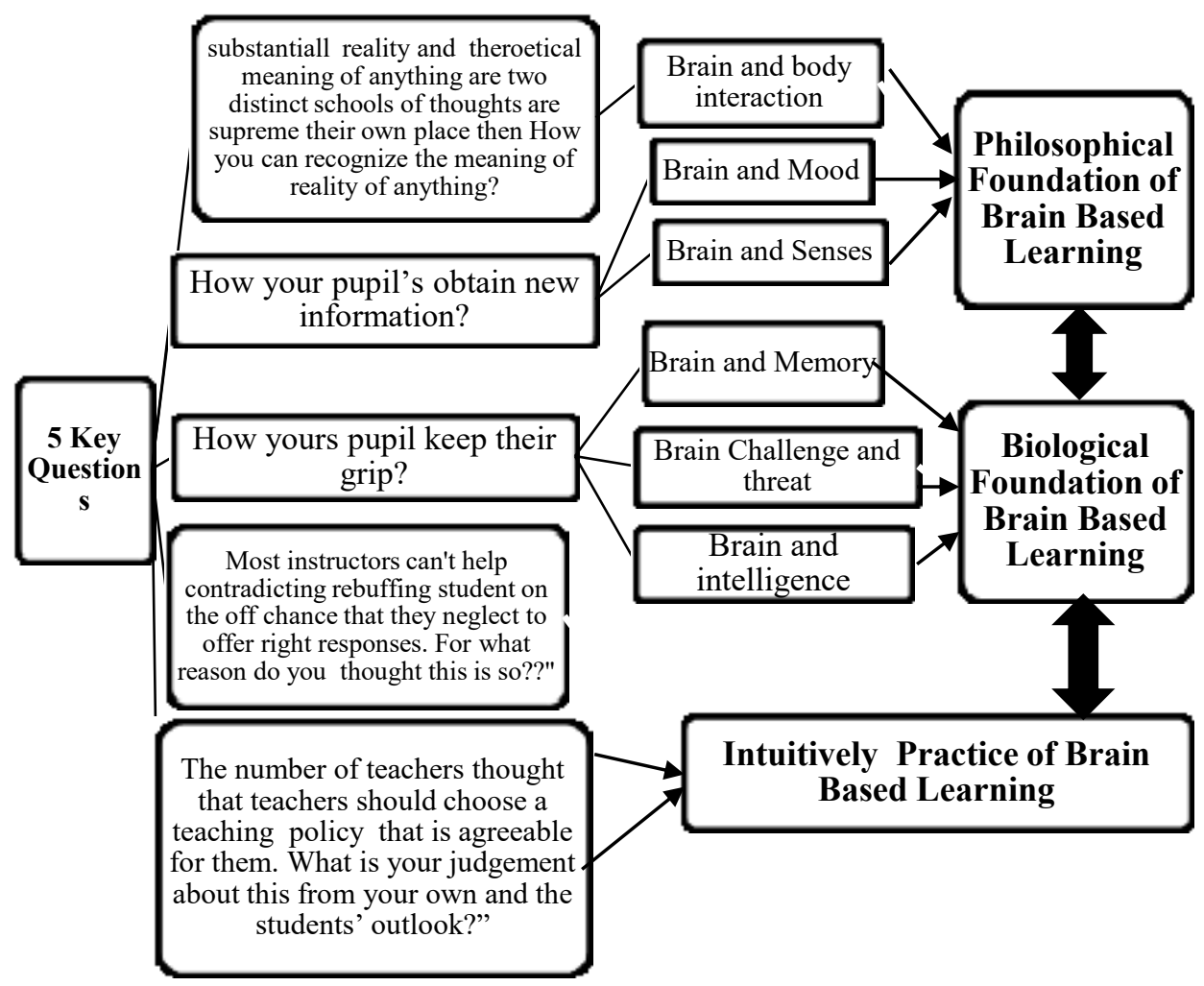

Figure 3. Thematic Analysis

\subsection{Intellectual and Remembrance}

"....... students sort out and stock knowledge that is based on whether it is heavily deposited in framework or is in complacent to daily life practices". Teachers believed that when the mind, body, and feelings are all involved, thinking arises. Perception also has an aspect in the thinking mode. Perception is generated by non-observing learning that was distinguished throughout a 
person's lifetime. This is absolute remembrance and has no characteristic of way of talking affiliated with it.

\subsection{Intellectual and Mentality}

"...... two ways through which their student accord latest instruction. It means they stock their information in accord to a particularized position, occasion, or chapter which is commonly developed from book learning and academic work". Study in vocabulary provides learners innumerable time to invent intimate junction. Teachers used multiplex recognition track to encourage numerous skills: this include the use of real-life imitation, thematic information, collaborative contextually study and a target on multiform mentality. Students activate multiform recognition systems when such methods are used, that help with learning incorporation. In the acknowledgement of another inquiry, teachers should decline a teaching approach that is appropriate for them, thought by majority of teachers. What is your assumption about this from your own and the students' view?" Based on the inquisition strike, the contributors categorized a domain of feedback to the matter of choosing teaching approaches, with many allegations that a caviling controversy in this amendment was the students' recognition. This was apparently adverse to the teachers' acknowledgement in the conversation, where they admit them barren to teach according to rule their adequate teaching approach. This means our brain is generally referred with evolution, not guidance. It is the brain's perfection way to protect someone life. The intellect will focus on guidance that is solitary recognized in the direction of considerable moreover apart even the general adaptation of brain charge have been plaintive.

\section{Discussion}

Three significant subjects, for example, "body and Mind connection", "brain and Moods" and "mind and senses" were utilized as the philosophical establishment of brain based learning since it was affirmed that this epistemic ramifications of acknowledgment is considered as more significant than the perceptual colleague and self-information of a person. It may be deduced along these lines that awareness, un-cognizance or pseudo-awareness are straightforwardly connected with the way of thinking of realism. Since every one of these parts of brain affirmed that it goes about as physical property of a person. It was additionally discovered that there is generally a little physical distinction was noted between un-cognizant and pseudo-cognizant perspective. This idea is crafted by Jensen (2005), Klinek (2009), and Kriegel (2014). They depicted realism and dualism school of musings. Likewise, the idea of "cognizance" and "obviousness" turned out in the advanced time of examination about the mind since it gives a reasonable image of brain's job in the reasoning 
and learning procedure of a person. These two scholarly powers of human were altogether tried in the nineteenth century by Kriegel (2014). This idea was legitimately connected with a mental hypothesis of "induction" that turned out through the exertion of Locke in nineteenth century (Fatima, 2017). Similarly, another mental hypothesis of "hiking" procedure of the person that explained the job of continuous improvement of person that relies upon the natural adjustment and this intriguing thought was straightforwardly connected with the Darwin's survival fittest in $19^{\text {th }}$ century. It was seen that some other way of thinking of mind which is straightforwardly connected with the structure and elements of brain, for example, observation and survival of fittest hypothesis were likewise connected with brain based learning (Fatima, 2019).

Additionally through topical examination, three subjects, for example, "mind and endurance mode", "memory" and "knowledge" had been advanced that demonstrated that brain based learning has natural/biological establishment. Caine et al. (2005) proposed twelve basic detects that grounded on broad arrangement of investigation decisions from cognizance to neuroscience. Neuroscience likewise determines with total carefulness how the brain, perception and casing of reference are converged and corresponded how these miseries the way through which we can procure any information. Another significant purpose for this impression is that brain agents continually have no equivalent assessment with respect to one another's conclusions. Teachers considered themselves to be a guide rather than rebuffing the understudies (Fatima et al., 2018). They plainly proposed the ramifications of discipline on understudies' feelings (Fatima \& Ali, 2019). Educators exhibited that they were concentrating more on understudies' inclinations contrasted with instructors favored method for educating (Fatima, Ali \& Fatima, 2018).

In the acknowledgement of this interrogation "maximum teachers contradict with fatiguing students whereas they decline to commit proper feedback. For what reason do you think this is pretended?" The attendant in their response accepts their controversy with the allegation purposely intended the word "distress, terror and depletion of possession". This propound that they are familiar of the consequence of infliction on the students' despair and identify with how de-motivating it can be to a student exacting to acquisition the equitable solution. Hassan (2013) mentioned the contrary consequence of punishment in the origin of brain indelicate attainments in which dare admit learning and infliction produce a threat that prevail students' affection, threatens their innervations and invalidate the learning procedure. Just as sensuality threatened, confiscation generates a stressful setting encompassed the students (Caine et al., 2005). They assert that while balanced expanse of stress will 
discharge a hormone to help in the learning procedure, a stressful location will outcome in too much hormone being discharge per severely and this discordantly influence the brain, body and immunity system (Fatima, 2017). Most importantly, teachers showed that they were exigent to express confrontation and threat in attainments to the communal and responsive appearance of learning (Ali et al., 2018). Approximate confiscation, opinion is also regarded as a benevolent of threat that anticipates learning. It alters personalized emotions as a completion of embarrassment that decreased one's consistent of certainty (Jensen, 2006). Against, critique referred to by the contributor was illustrated by them as productive appreciation that is capable to protest the students to activate learning (Cercone, 2006).

\section{Conclusions}

Based on topical and content investigation, following ends have been uncovered;

1. Themes such as brain and body interaction, moods and senses showed that brain based learning theory has philosophical foundation because authenticity, optimism, realism, dualism, naturalistic, cognizant, oblivious or pseudocognizant and constructivism were legitimately related with the brain based learning approach in the learning process. It was confirmed by literature review as well through the lived experiences of university teachers that brain based learning has strong philosophical foundation.

2. Themes such as brain and intelligence, memory, challenges and threat are directly linked with the biological foundation of brain based learning. Similarly, educators don't completely measure the brain naturally in light of the fact that mind revelation is calm and a youthful ground in training learning procedure. Instructors have been rehearsing brain based adapting instinctively however they are not ready to express an unmistakable method of reasoning for their activities yet they are as yet ready to practice brain based adapting successfully.

\section{Recommendations}

1. The results demonstrate that instructors have information, accept and do practice mind based learning in their classrooms. Anyway the educators likewise demonstrate that should be officially prepared and be given adequate time to pick up data and execute mind based learning procedures in their classrooms.

2. The school specialists ought to give chances to staff improvement. Instructor training courses ought to incorporate hypothetical premise of cerebrum based learning and furthermore give extension to its execution. 
3. As wanted by the instructors in this examination, they would anticipate a proper preparing on brain based learning.

\section{References}

Ali, S., \& Fatima, F. (2016). Teachers' insights about the eminence of performance appraisal and its effect on the commitment and job skills of the teachers at university level. Journal of Socialomics, 5(3), 169-179. doi:10.41 72/2167-0358.1000169

Ali, S., \& Fatima, F. (2016). Comparative Analysis of Safety and Security Measures in Public and Private Schools at Secondary Level. Journal of Socialomics, 5(3), 159-169. doi:10.41 72/2167-0358.1000169

Ali, S., \& Fatima, F. (2015). Comparative Study of Public and Private Educational Institutes towards the Recruitment, Retention and Reward of Their Teachers. Journal of literature, languages and linguistics, An international Peer-Reviewed journal, 14(2), 51-56

Ali, S., Zamir, S., Fatima, F., \& Fatima, S. (2018). Comparative Analysis of Communication Climate and Self-Efficacy of Teachers at University Level. Journal of Management Sciences, 11(3), 186-212

Bhalla, M. (1999).Visual-Motor Recalibration in Visual Slant Perception. Diary of Test Psychology, 25(8), 1076-1096

Damasio, A. (1999). The sentiment of what occurs: Body and feeling in the checking of cognizance. New York: Harcourt Brace.

Fishback, S. (1999). Learning and the brain. Adult learning, 10(2), 18-23.

Fatima, F. (2019). Teachers' Attitude towards Brain Based Learning and Its Effect on Achievement Motivation of Students at University Level $(\mathrm{PhD}$ Dissertation). Department of Education, Faculty of Social Sciences, National University of Modern Languages, Islamabad. Retrieved from http://prr.hec.gov.pk/jspui/bitstream/123456789/11250/1/Fozia\%20Fatim a_Edu_2019_NUML_PRR.pdf

Fatima, F. (2019). Teachers' Attitude towards teamwork at university level. Governance and Management Review (GMR), 4(1), 56-75. 
Fatima, F. (2017). Teachers' attitude towards Brain based Learning and its effect on the achievement motivation of the students at university level. Sci.Int. (Lahore), 29(1), 315-324.

Fatima, F. (2016). Comparative Analysis of National and International Approaches and Acuities of Child Labour Within UK, USA, India and Pakistan. American Journal of Educational Research, 4(18), 1271-1280. doi: 10.12691/education-4-18-5

Fatima, F., \& Ali, S. (2019). Descriptive Analysis of Teachers' Perception about supportive and defensive communication climate along with their selfefficacy at University level. Governance and Management Review (GMR), 4(2), 56-74.

Fatima, F., \& Ali, S. (2017). Attitude of prospective teachers towards the curriculum and teaching learning process of pre-service education programs in Islamabad, Journal of Contemporary Teacher Education (JCTE), 1(1), 48-64.

Fatima, F., Ali, S. (2016). The Impact of Teachers' Financial Compensation on their Job Satisfaction at Higher Secondary Level. Journal of Socialomics 5(3), 164-174. doi:10.41 72/2167-0358.1000164

Fatima, F., \& Zamir, S. (2015). Teachers' perception about pre-service teacher education programs at higher secondary level. Journal of literature, languages and linguistics, An international Peer-Reviewed Journal, $12(2), 66-75$

Fatima, F., Ali, S., \& Fatima, S. (2018). Prohibition of child labour leading to delinquent behaviour in the constitution of Islamic Republic of Pakistan 1973. Pakistan Administrative Review, 2(4), 383-396.

Fatima, F., Zamir, S., Ali, S., \& Fatima, S. (2018). Effect of Demographic Factors over the Achievement Motivation of Students at university level in Islamabad. Journal of Managerial Sciences, 11(3), 213-236.

Gardner, H. E. (1999). Different ways to deal with comprehension. In C. M. Reigeluth (Eds.), Instructional-structure hypotheses and models: another worldview of instructional hypothesis (Volume II, pp.69-89). Mahwah, NJ: Lawrence Erlbaum. 
Gurian, M., \& Stevens, K. (2004).With young men and young ladies in mind. Educational Leadership, 62(3), 21-26.

Hart, L. (1983). Human cerebrum, human learning. New York: Longman.

Hassan, R.W. (2013). Brain Compatible Classroom: An examination concerning Malaysia's Auxiliary School Science Teachers' Pedagogical Belief and practices (PhD Dissertation). La Trobe University, Bundoora, Victoria, 3086, Austrial

Hattie, J. (1992). Self-idea. Hillsdale, NJ: L. Earlbaum Associates.

Hill, L. S. (2001). The mind and cognizance: Sources of data for comprehension grown-up learning. New Directions for Adult and Continuing Education, $8,73-81$.

Jensen, E. (2000).Brain-based learning (Rev. ed.). San Diego, CA: The Brain Store.

Jensen, E. (2005). Instructing in view of the Brain, second Edition. Association for Supervision what's more, Curriculum Development. Retrieved from http://www.ascd.org/productions

Jensen, E. (2006).Enriching the cerebrum: How to amplify each student's potential (first ed.). San Francisco: Jossey-Bass, A John Wiley and Sons.

\section{Citation of this Article:}

Fatima, F., \& Ali, S. (2020). Philosophical and Biological Foundation of Brain Based Learning: A Phenomenological Approach. International Journal of Innovation in Teaching and Learning (IJITL), 6(2), 1-16. 